\title{
Correction to: Prevalence of problematic smartphone usage and associated mental health outcomes amongst children and young people: a systematic review, meta- analysis and GRADE of the evidence
}

\author{
Sei Yon Sohn ${ }^{1}$, Philippa Rees ${ }^{2}$, Bethany Wildridge ${ }^{1}$, Nicola J. Kalk ${ }^{3,4 \dagger}$ and Ben Carter ${ }^{5,6^{*+}+}$
}

Correction to: BMC Psychiatry 19, 356 (2019)

https://doi.org/10.1186/s12888-019-2350-x

Following publication of the original article [1], the authors identified an error in the author name of Sei Yon Sohn. The previous amendment can be found on https://doi.org/10.1186/s12888-019-2393-z.

The incorrect author name is: Samantha Sohn.

The correct author name is: Sei Yon Sohn.

The author group has been updated above and the original article [1] has been corrected.
Published online: 22 January 2021

\section{Reference}

1. Sohn S, et al. Prevalence of problematic smartphone usage and associated mental health outcomes amongst children and young people: a systematic review, meta-analysis and GRADE of the evidence. BMC Psychiatry. 2019;19: 356. https://doi.org/10.1186/s12888-019-2350-x.

\footnotetext{
Author details

'Institute of Psychiatry Psychology and Neuroscience, King's College London, London, UK. ${ }^{2}$ Institute of Child Health, University College London, London, UK. ${ }^{3}$ Department of Addictions, Institute of Psychiatry Psychology and Neuroscience, King's College London, London, UK. ${ }^{4}$ South London and Maudsley NHS Foundation Trust, London, UK. ${ }^{5}$ Department of Biostatistics, and Health Informatics, Institute of Psychiatry, Psychology and Neuroscience, King's College London, Denmark Hill, De Crespigny Park, London SE5 8AF, UK. ${ }^{6}$ Cochrane Skin Group, School of Medicine, Nottingham University, Nottingham, Nottinghamshire, UK.
}

* Correspondence: ben.carter@kcl.ac.uk

${ }^{\dagger}$ Nicola J. Kalk and Ben Carter contributed equally to this work.

${ }^{5}$ Department of Biostatistics, and Health Informatics, Institute of Psychiatry,

Psychology and Neuroscience, King's College London, Denmark Hill, De

Crespigny Park, London SE5 8AF, UK

${ }^{6}$ Cochrane Skin Group, School of Medicine, Nottingham University, Nottingham, Nottinghamshire, UK

Full list of author information is available at the end of the article

C C The Author(s). 2020 Open Access This article is licensed under a Creative Commons Attribution 4.0 International License, which permits use, sharing, adaptation, distribution and reproduction in any medium or format, as long as you give appropriate credit to the original author(s) and the source, provide a link to the Creative Commons licence, and indicate if changes were made. The images or other third party material in this article are included in the article's Creative Commons licence, unless indicated otherwise in a credit line to the material. If material is not included in the article's Creative Commons licence and your intended use is not permitted by statutory regulation or exceeds the permitted use, you will need to obtain permission directly from the copyright holder. To view a copy of this licence, visit http://creativecommons.org/licenses/by/4.0/ The Creative Commons Public Domain Dedication waiver (http://creativecommons.org/publicdomain/zero/1.0/) applies to the data made available in this article, unless otherwise stated in a credit line to the data. 